\title{
LA MALA FE Y EL FRAUDE EN EL DERECHO COLOMBIANO DE SEGUROS*
}

\section{BAD FAITH AND FRAUD IN COLOMBIAN INSURANCE LAW}

\author{
DANIEL VÁSQUEZ VEGA* \\ Fecha de recepción: 27 de octubre de 2016 \\ Fecha de Aceptación: 19 de abril de 2017 \\ Disponible en línea: 30 de junio de 2017
}

\section{Para Citar este articulo/To cite this article}

Vásquez Vega, Daniel, La mala fe y el fraude en derecho colombianos de seguros, 46 Rev.Ibero-Latinoam.Seguros, 15-35 (2016). https://doi. org/10.11144/Javeriana.ris45.mffd

doi:10.11144/Javeriana.ris46.mffd

* Artículo de reflexión.

** Abogado de la Universidad CES (Col.), Especialista en Derecho de Seguros de la Pontificia Universidad Javeriana (Col.), LLM de UCL (R. U.), profesor y coordinador del área de derecho privado de la Universidad EAFIT, abogado independiente.Contacto: dvasqu22@eafit.edu.co daniel@ vasquezvega.com 


\section{RESUMEN}

El contrato de seguro es uno en el que la buena fe tiene especial preponderancia y la misma se encuentra presente a lo largo de toda la relación aseguraticia, esto es, en la etapa precontractual, durante la vigencia del seguro e incluso después de ocurrido un siniestro. De igual manera, así como el derecho promueve la buena fe, también procura disuadir el fraude durante todas las mismas etapas. El derecho colombiano no es ajeno a esto y en este sentido al regular el contrato seguro establece una serie de reglas que promocionan la buena fe y desincentivan y castigan la mala fe y el fraude. Estas reglas son, principalmente, las siguientes: a) el deber de declarar sinceramente el estado del riesgo; b) la prohibición de contratar seguros con causas o motivos ilícitos; c) la prohibición de cubrir o asegurar los siniestros ocasionados intencional o dolosamente por el tomador, asegurado o beneficiario d) el deber de presentar las reclamaciones en buena fe; y e) la existencia del principio indemnizatorio en los seguros de daños y la consecuente regulación del sobreseguro y de la coexistencia de seguros.

Palabras clave: Contrato de seguro; Buena fe; Mala fe; Fraude; Reticencia e inexactitud; coexistencia de seguros; sobreseguro. 


\begin{abstract}
Insurance is a contract in which the good faith has special prominence and it is present throughout the entire contractual relationship, that is, in the precontractual stage, during the insurance period and even after the occurrence of the insured event. Similarly, as well as the law promotes good faith, it also seeks to deter fraud through all the same stages. Colombian law is no stranger to this and in this sense when it regulates the insurance contract it establishes a set of rules that promote good faith and discourage and punish bad faith and fraud. These rules are mainly the following: a) the duty to disclose and not misrepresent the risk; b) the prohibition on taking insurance based on illegal causes or motives; c) the prohibition to cover or secure claims caused intentionally or willfully by the policyholder, insured or beneficiary d) the duty to file claims in good faith; and e) the existence of the indemnity principle in property insurance and the consequent regulation of coexistence and overinsurance.
\end{abstract}

Keywords: Insurance contract; good faith; bad faith; fraud; non-disclosure and misrepresentation; coexistence of insurance; overinsurance.

\title{
SUMARIO
}

1. INTRODUCCIÓN - 2. TIPOS DE FRAUDE - 3. EL DOLO COMO VICIO DEL CONSENTIMIENTO EN EL CONTRATO DE SEGURO - 4. LA CONTRATACIÓN DOLOSA VS. LA CAUSA ILÍCITA - 5. EL SINIESTRO INTENCIONAL Y LA MALA FE EN LA RECLAMACIÓN - 6. EL PRINCIPIO INDEMNIZATORIO, EL SOBRESEGURO Y LA COEXISTENCIA DE SEGUROS - 7. CONCLUSIONES - BIBLIOGRAFÍA 


\section{INTRODUCCIÓN}

La buena fe se encuentra profundamente imbuida dentro del derecho colombiano. Su consagración ha sido expresa desde el artículo 1603 del Código Civil, y, legislaciones posteriores como el Código de Comercio, han resaltado su importancia en artículos como el 863 y el 871 , en los cuales se dispone que debe estar presente aun en la etapa precontractual. La presencia de la buena fe fue incluso consagrada en el artículo 83 de la Constitución Política y, doctrinantes como la profesora Neme (2006) han expuesto de manera detallada los deberes que se desprenden de ella, así como los remedios que se derivan del incumplimiento de estos.

Por su parte, el contrato de seguro ha sido fuente de escenarios en los cuales el postulado de buena fe ha podido brillar en su máximo esplendor. Tal ha sido su relevancia que la Corte Suprema de Justicia y la Corte Constitucional han indicado que en el ámbito aseguraticio debe hablarse de ubérrima buena $\mathrm{fe}^{1,2}$.

Por cuestiones de lenguaje, con facilidad se podría pensar que la ausencia de buena fe implica la presencia de mala fe, sin embargo, como recientemente lo señaló el profesor Carlos Ignacio Jaramillo (2016, págs. 185-187), esto no siempre es cierto, pues la buena fe ha sido desarrollada en vertientes objetivas y subjetivas que impiden "expresar que buena fe es todo lo contrario a mala fe, y que esta última, pari passu, es el anverso de la buena fe" (pág. 186), por lo cual "si bien es cierto todas las actuaciones de mala fe son atentatorias y, por ende vulneran a la buena fe, no todos los comportamientos que no se ajusten a la buena fe, per se, necesaria y estrictamente son de mala fe" (pág. 187).

Sobre la distinción entre las dos tipologías de la buena fe, tanto Neme (2009), como Jaramillo (2016, págs. 192-197), han indicado que

1 Esta afirmación es frecuente tanto en la jurisprudencia (como por ejemplo en la sentencia C-232 de 15 de mayo 1997 de la Corte Constitucional, o en la sentencia de 2 de agosto de 2002 de la Corte Suprema de Justicia), como en la doctrina (Ossa Gómez, 1991, pág. 77).

2 Un análisis interesante sobre el carácter ubérrimo de la buena fe en materia de seguros puede encontrarse en la monografía de Johan Hendrik Botes (From Good Faith to Utmost Good Faith in Marine Insurance, 2006), en ella se propone que la expresión uberrimae fidei fue acuñada por los anglosajones, pero no conlleva nada distinto a la buena fe presenta en el derecho del continente europeo. 
la buena fe objetiva ha sido entendida como un principio del que se deriva un modelo de comportamiento al que se deben ceñir las personas, entre otros, en la celebración y ejecución de contratos. De este modelo se derivan deberes tales como los de diligencia, probidad, seriedad, transparencia, responsabilidad, entre otros, y el incumplimiento de los mismos, como ocurre con los deberes en general, puede darse de forma doloso (intencional) o culposa.

Por su parte, la buena fe subjetiva ha sido entendida como un estado de ignorancia y error en el cual se encuentra un sujeto respecto de un derecho que cree propio o respecto de una situación que puede estar lesionando a un tercero. Se trata pues de un estado psicológico consistente en que el sujeto cree estar actuando adecuadamente o que su comportamiento no lesiona los intereses de otro.

Lo anterior implica que el incumplimiento de la buena fe objetiva no siempre implicará necesariamente mala fe, toda vez que el postulado puede incumplirse tanto con dolo, como con culpa; pero no sucede lo mismo con la buena fe subjetiva, cuya ausencia implicará un comportamiento de mala fe, toda vez que el sujeto no desconoce la incorrección de su comportamiento o la lesión que este puede causar.

En este sentido, mala fe es más cercano a la definición de dolo, en el sentido propuesto por el artículo 63 del código civil ${ }^{3}$, que a la mera ausencia de buena fe y puede equipararse, como se verá, con ciertos comportamientos fraudulentos (entendido el fraude en un sentido extrapenal) en que pueden incurrir tomadores, asegurados o beneficiarios.

Si bien la buena fe ha sido objeto de numerosos estudios ${ }^{4}$, la regulación de la mala fe y del fraude parece no haber generado, por lo menos

3 El artículo 63 del Código Civil también define el dolo al establecer que este "consiste en la intención positiva de inferir injuria a la persona o propiedad de otro". Al respecto la doctrina ha considerado que el dolo se extiende, en las hipótesis de responsabilidad extracontractual, a aquellos casos en los cuales se sabe que la conducta puede causar el daño así la intención de la misma no sea causarlo, y en las hipótesis de responsabilidad contractual, al incumplimiento deliberado así no tenga la intención de causar daño (Tamayo Jaramillo, 2007, págs. 218-220).

4 Basta ver, a manera de ejemplo, los interesantes análisis de Jaramillo (2011), Ordóñez (2004), Ossa (1991), entre otros. 
como eje temático, el mismo interés ${ }^{5}$. A pesar de esto, en conversaciones con agentes pertenecientes al sector asegurador, y sus intervenciones en procesos judiciales, es posible identificar que no siempre se tienen claras las reglas que aplican a los diversos supuestos de mala fe y fraude, pasando algunas de ellas por alto o confundiendo las reglas que aplican a cada hipótesis en particular. Por este motivo este artículo explorará cómo ha sido sancionada la mala fe de los tomadores, asegurados o beneficiaros que pretenden defraudar a compañías aseguradoras, con el propósito de obtener claridad sobre sus reglas y poder analizar la coherencia y adecuación de las mismas.

Con esto en mente, se analizarán las principales reglas que, en materia de seguros, promocionan la buena fe y desincentivan y castigan la mala fe y el fraude. Estas reglas son, especialmente, las siguientes: a) el deber de declarar sinceramente el estado del riesgo, lo que incluye no inducir al asegurador en error ${ }^{6}$; b) la prohibición de contratar seguros con causas o motivos ilícitos ${ }^{7}$; c) la prohibición de cubrir o asegurar los siniestros ocasionados intencional o dolosamente por el tomador, asegurado o beneficiario ${ }^{8} \mathrm{~d}$ ) el deber de presentar las reclamaciones en buena $\mathrm{fe}^{9}$; y e) la existencia del principio indemnizatorio en los seguros de daños y la consecuente regulación del sobreseguro y de la coexistencia de seguros ${ }^{10,11}$. Sin embargo, antes de comenzar con su estudio, se hará un corto recuento de los tipos de fraude más comunes.

\section{TIPOS DE FRAUDE}

Con el fin de poder entender la finalidad de algunas de las normas que se describirán, será necesario, antes de comenzar con su análisis, hacer algunas aclaraciones sobre el fraude en el contrato de seguro, en especial sobre sus modalidades o la forma en que se puede clasificar.

5 Salvo un estudio del profesor Ordóñez publicado en 2005 (El Tratamiento Civil de la Mala Fe del Asegurado en el Contrato de Seguro), es escasa la literatura al respecto.

6 Regulado a partir del artículo 1058 del Código de Comercio.

7 Establecida de forma general para todos los contratos en el artículo 1524 del Código Civil.

8 Establecida en el artículo 1055 del Código de Comercio.

9 Establecido en el artículo 1078 del Código de Comercio.

10 Establecido en los artículos 1076 y 1091 y siguientes del Código de Comercio.

11 Si bien existen más normas y reglas que hacen referencia a la buena fe y al fraude, estas no serán objeto de estudio de este escrito. 
Los fraudes normalmente se catalogan en dos categorías: el fraude suave u ocasional y el fraude duro u organizado ${ }^{12}$.

El primero consiste en inflar el costo de una reclamación derivada de un siniestro que realmente ocurrió o en incluir en la reclamación daños que existían o se habían producido antes o en otro evento y es perpetuado normalmente por defraudadores ocasionales. Se está entonces ante situaciones en las cuales, normalmente, el seguro no fue contratado con un propósito fraudulento, ni se causó el siniestro de forma intencional, sino que el asegurado o beneficiario 'cae en la tentación' de aprovecharse de un siniestro en principio cubierto para obtener una indemnización adicional a la debida.

El segundo tipo de fraude consiste en una estafa planeada en la cual se simula o provoca la ocurrencia de un siniestro y es realizado, por regla general, por bandas organizadas. En estos casos la mala fe puede existir desde el momento mismo de la contratación del seguro, pues se toma a sabiendas de que se va a perpetuar el fraude, o puede haberse tomado el seguro sin esta intención, pero luego se maquina un siniestro para pretender la indemnización.

Existe además una tercera modalidad en la cual el fraude es llevado a cabo por terceros que simulan o provocan un siniestro para afectar el seguro de un asegurado inocente (Fernández, Niño, \& Cabrera, 2005, pág. 354).

Como se indicará, las distintas normas que se analizarán sirven para prevenir o castigar alguna de estas tres modalidades.

\section{EL DOLO COMO VICIO DEL CONSENTIMIENTO EN EL CONTRATO DE SEGURO}

El artículo 1502 del Código Civil establece que "[p]ara que una persona se obligue a otra por un acto o declaración de voluntad es necesario

12 Sobre los tipos de fraude que se pueden presentar en las relaciones aseguraticias se encuentran, en la doctrina colombiana y latinoamericana, los trabajos de Fernández, Niño \& Cabrera (El fraude a los seguros, 2005, pág. 352), de de la Espriella (Fraude en seguros: una aproximación al caso colombiano, 2013, pág. 566) y de Díaz Bravo (El fraude y su incidencia en el contrato de seguro, 2009, pág. 31). 
que... su consentimiento no adolezca de vicio". El mismo estatuto en el artículo 1508 establece los tres vicios de los que puede adolecer el consentimiento, estos son, el error, la fuerza y el dolo. Y, por último, el artículo 1741 determina que el consentimiento viciado produce la nulidad relativa y da derecho a la rescisión del acto o contrato ${ }^{13}$. El dolo, que en materia de mala fe y fraude es el vicio que más interesa, consiste en toda "maquinación, trampa, artificio o astucia encaminados a[...] crear en la mente de una persona[...] un móvil o razón para consentir, móvil o razón que en realidad no existe, que es ilusorio y pernicioso" (Ospina Fernández \& Ospina Acosta, 2005, pág. 202), esto es, en la inducción intencional en error.

En Colombia el contrato de seguro tiene un régimen especial que reemplaza, parcialmente, la institución de los vicios del consentimiento descrita en el párrafo anterior. Se trata del deber del tomador debe declarar sinceramente los hechos y circunstancias que determinan el estado del riesgo, so pena de nulidad relativa y la retención de la prima a título de pena ${ }^{14}$. La parte de la institución de los vicios del consentimiento reemplazada por el deber del tomador de declarar fielmente el estado del riesgo, es la del error y el dolo que afectan el consentimiento del asegurador, pero la institución del Código Civil sigue operando en los casos en los cuales el consentimiento del asegurador está viciado por fuerza y en todos los casos en los cuales el consentimiento viciado es el del tomador (Ossa Gómez, 1991, pág. 325 y ss) $)^{15}$.

Dicho régimen especial se encuentra establecido en los artículos 1058 y 1059 del Código de Comercio, los cuales indican que quien desee contratar un seguro tiene el deber de "declarar sinceramente los hechos o circunstancias que determinan el estado del riesgo, según el cuestio-

13 El régimen general de vicios del consentimiento es una de las principales instituciones derivadas del principio de buena fe (Zimmermann \& Whittaker, 2000).

14 Se dice que las normas generales del Código Civil son insuficientes teniendo en cuenta las características especiales del contrato de seguro y que esto amerita la regulación especial expedida para el contrato de seguro (Ossa Gómez, 1991, págs. 326-327 y 333-334).

15 Para el profesor Ordóñez (2004, págs. 24-28) el deber de declarar fielmente el estado del riesgo ni siquiera suple el régimen de los vicios del consentimiento en los casos de dolo, sino que se limita a regular el tema del error inducido. Tal afirmación resulta confusa porque, como se indicó, el dolo ha sido definido por la doctrina (Ospina Fernández \& Ospina Acosta, 2005, pág. 205) como aquellas maquinaciones encaminadas a inducir a la contraparte contractual en error. En este sentido, los términos 'error inducido' y 'dolo' parecerían estar haciendo referencia al mismo fenómeno. 
nario que le sea propuesto por el asegurador" y aclaran que cualquier "reticencia o la inexactitud sobre hechos o circunstancias que, conocidos por el asegurador, lo hubieren retraído de celebrar el contrato, o inducido a estipular condiciones más onerosas, producen la nulidad relativa del seguro"16.

Este régimen es el primer paso encaminado a defender a compañías de seguros frente a aquellos casos en los cuales el seguro es contratado con miras a defraudarlas, toda vez que sanciona los casos en los cuales son inducidas en error por el tomador.

El incumplimiento del deber puede darse por vía de reticencia o de inexactitud. Reticencia significa retener o no decir algo, inexactitud se refiere a dar información incorrecta o inexacta (Ordóñez Ordóñez, 2004, págs. $20-21)^{17}$. Los hechos, como lo señala la ley, deben ser aquellos "que, conocidos por el asegurador, lo hubieren retraído de celebrar el contrato, o inducido a estipular condiciones más onerosas". Aquellos que cumplen esta condición son referidos por la doctrina como hechos 'relevantes' (Ossa Gómez, 1991, págs. 330-331) ${ }^{18}$.

Como se indicó, el artículo 1058 remplaza el régimen general en materia de dolo y error. Una de las principales modificaciones que aquél implica respecto de este, es que el que haya o no intención fraudulenta por parte del tomador es irrelevante y el contrato será anulable, tanto en los casos en los que el tomador incumplió su deber de manera dolosa, como culposa, pues la buena fe exige mucho más que ausencia de dolo ${ }^{19}$.

16 El segundo párrafo del artículo 1058 establece que en los casos en los que "la declaración no se hace con sujeción a un cuestionario determinado, la reticencia o la inexactitud producen igual efecto si el tomador ha encubierto por culpa, hechos o circunstancias que impliquen agravación objetiva del estado del riesgo."

17 En el mismo sentido había definido Ossa (1991, pág. 330) estas expresiones.

18 La Corte Suprema de Justicia, en sentencia de 12 de septiembre de 2002, indicó que el requisito de relevancia no es objetivo, sino subjetivo, esto es, no es que se deba probar que una aseguradora diligente no hubiese celebrado el contrato, sino que la aseguradora involucrada en el caso concreto no habría suscrito el contrato o lo habría hecho en términos diferentes si hubiera sabido del hecho no informado. La prueba de la relevancia se ha hecho más fácil, por la 'presunción de relevancia' creada por la Corte Suprema en sentencia de 01 de septiembre 2010, cuando estableció que, a fin de demostrar la relevancia que un determinado hecho o circunstancia tenían para el asegurador, era suficiente comprobar si se había preguntado por aquellos hechos o circunstancias en el cuestionario.

19 Este es un claro ejemplo de como la ausencia de buena fe no siempre implica mala fe (Jaramillo Jaramillo, 2016, pág. 187). Por ejemplo, el profesor Efrén Ossa indica, hablando de la declaración del 
Sin embargo, desde hace algunos años, la Corte Constitucional parece haber entendido el alcance del artículo 1058 en un sentido diferente. En sentencias como la T-521 de 2012 y la T-222 de 2014 la Corte ha indicado que el contrato de seguro solamente se encuentra viciado de nulidad en aquellos casos en los cuales el tomador obró con mala fe, esto es, en aquellos casos en los cuales el incumplimiento del tomador haya sido doloso ${ }^{20}$.

Lo anterior tiene fuertes implicaciones frente a la defensa de las compañías aseguradoras en casos de fraude, toda vez que el que el mero incumplimiento culposo del deber de información bastara para pretender la nulidad del contrato, facilitaba la defensa en aquellos casos en los cuales la compañía aseguradora consideraba que el error había sido inducido por una maquinación del tomador (esto es, dolo), pero no contaba con las pruebas suficientes para demostrar judicialmente la creencia, toda vez que dicho dolo no debía ser probado.

Esto resulta más gravoso aun si se tiene en cuenta que, por lo menos para la doctrina especializada, la carga de la prueba del dolo o la culpa variaba dependiendo de si se había suministrado o no un cuestionario, así: cuando no hay cuestionario el asegurador debe demostrar que la reticencia o inexactitud del tomador fue con dolo o culpa, mientras que cuando el asegurador sí lo suministró es el tomador quien debe demostrar que él actuó con diligencia y que por lo tanto su error fue inculpable (Ossa Gómez, 1991, págs. 337-339) ${ }^{21}$, circunstancia supremamente relevante porque en el último caso el contrato no puede ser rescindido, sino que tan solo es posible reducir el importe de la indemnización. En sentido contrato, la Corte Constitucional en las sentencias referidas no diferencia la carga de la prueba en uno y otro caso.

estado del riesgo, que esta "no solo debe ser fruto de la honestidad, sino de la más esmerada diligencia del tomador" y que a esto se refiere la Corte Suprema de Justicia cuando en sentencia de 26 de julio de 1976 indica que los dos primeros incisos del artículo 1058 del Código de Comercio reiteran y exigen la buena fe "aún con mayor severidad al tomador del seguro" (1991, pág. 328).

20 Esta postura ha sido reiterada en las sentencias T-830 de 2014, T-919 de 2014, T-393 de 2015, T-316 de 2015, T-684 de 2015, T-570 de 2015, T-058 de 2016, T-240 de 2016, T-609 de 2016 y T-501 de 2016.

21 Sin embargo, el profesor Ordoñez (2004, págs. 33-35), aunque acepta que cuando no hay cuestionario el asegurador debe demostrar que el tomador fue negligente, mientras que cuando sí lo hay es el tomador el que debe demostrar que actuó de forma diligente y sin culpa, señala que la redacción del código en este punto es oscura y técnicamente imprecisa. 
Ahora, esta interpretación sui generis de la Corte Constitucional parece haberse comenzado a rectificar en sentencias más recientes, como la T-570 de 2015, la T-058 de 2016 y la T-501 del mismo año. Habrá que esperar más pronunciamientos para ver si la rectificación se mantiene o si persisten las diferencias interpretativas entre la Corte Suprema de Justicia y la Corte Constitucional22.

Por otro lado, de manera complementaria, el artículo 1059 establece que, en adición a poder rescindir el contrato, la aseguradora también puede retener la prima a título de pena. La nulidad a ambos casos (culpa o dolo) se justifica en el incumplimiento del deber de información que se desprende del postulado de la buena fe. Sin embargo, que al asegurador se le permita retener la prima a título de pena incluso en los casos en los cuales el incumplimiento se dio de manera culposo ha sido criticado como un exceso del ordenamiento colombiano (Vásquez Vega, 2014) ${ }^{23}$. Esto, sin duda, se encuentra justificado en los casos de dolo, toda vez que expone al tomador no solo al no pago del siniestro, sino a la pérdida del precio, lo cual puede tener, por lo menos desde una perspectiva teórica, efectos disuasivos.

Por último, el cuarto párrafo del artículo 1058 aclara que el contrato no será anulable ni se puede reducir la indemnización "si el asegurador, antes de celebrarse el contrato, ha conocido o debido conocer los hechos o circunstancias sobre que versan los vicios de la declaración, o si, ya celebrado el contrato, se allana a subsanarlos o los acepta expresa o tácitamente".

En la célebre sentencia de 2 de agosto de 2002, la Corte Suprema de Justicia tuvo la oportunidad de hacer un interesante análisis de la regla

22 Para un análisis detallado sobre la interpretación del artículo 1058 por parte de la Corte Constitucional, ver el trabajo de grado de María del Pilar Begué Hoyos (Desarrollo jurisprudencial en sentencias de tutela de la Corte Constitucional sobre el deber precontractual de información en el contrato de seguro, 2017, Universidad EAFIT).

23 El que se permita la retención de la prima incluso en los casos de culpa es bastante cuestionable. El viejo Código de Comercio solo lo permitía en los casos de dolo y el proyecto de Código de Comercio 1958, que fue la base del actual código de 1971, parecería solo permitir la retención de la prima en los casos de mala fe. Incluso el texto discutido por el comité redactor del nuevo código hablaba de que la prima no podía ser retenida en los casos en los cuales el tomador acreditara su buena fe exenta de culpa. Pero, lamentablemente, la redacción definitiva nada dice al respecto, y no hay constancia en las actas del porqué se permitió la retención en estos casos. 
consagrada en el cuarto párrafo del artículo 1058. En dicha ocasión se debió resolver una disputa en la cual, entre otras cosas, las compañía de seguros no había acatado las sugerencias de uno de sus médicos de someter al potencial asegurado a exámenes médicos adicionales a los que ya había practicado, exámenes que, de haberlos practicado, le hubiesen revelado a la compañía aseguradora el estado real del riesgo que no había sido declarado por el candidato a tomador. En dicha ocasión la Corte consideró que el actuar de la compañía de seguros no había cumplido con la diligencia propia de un profesional y que esta falta había conllevado a que desconociese aquellos hechos o circunstancias sobre los que versaba los vicios de la declaración, lo cual, consecuentemente, condujo a que se frustrara la excepción de nulidad.

Sobre esta sentencia, parte de la doctrina (Ordóñez Ordóñez, 2003) ha manifestado inconformidad, pues considera que el actuar doloso del tomador no podía condonarse por el actuar culposo del asegurador. Si bien en principio esta crítica parecería acertada, en la sentencia no se encuentran manifestaciones de la Corte en las que la corporación reconociese que el quebrantamiento del postulado de la buena fe por parte del tomador hubiese sido doloso o fraudulento, razón por la cual, parecería más bien que, habiendo culpa de ambas partes, la Corte, apoyándose en el último párrafo del artículo 1058, había dado preponderancia a la culpa de la compañía de seguros. Si esto es cierto, nada obstaría para que si en una próxima ocasión la alta corporación tuviese que decidir un caso en el que se enfrentara el dolo del tomador, con una culpa del asegurador, prevaleciera la sanción a aquella, pues necesariamente resulta más reprochable un incumplimiento doloso del principio de buena fe, que un incumplimiento culposo del mismo.

Por último, no sobra recordar que la nulidad, como principal remedio por la inobservancia dolosa (y culposa) del deber precontractual de información, significa rescindir el contrato ab initio, por lo tanto, es irrelevante si no hay relación entre los hechos o circunstancias que no se dan a conocer y el evento que se reclama ${ }^{24}$.

24 Esta postura ha sido sostenida tradicionalmente por la doctrina, ver por ejemplo lo que al respecto indican Carlos Ignacio Jaramillo (2011, págs. 671-686) y Ordóñez (2004, págs. 46-47); y si bien también fue sostenida por la Corte Constitucional en su sentencia C-232 de 15 de mayo 1997, en algunos pronunciamiento recientes como la sentencia T-282 de 2013 ha sostenido la postura contraria. 
La institución, como se encuentra descrita, protege efectivamente a las compañías de seguros, entre otras cosas, frente a aquellas hipótesis de fraude duro en las cuales desde la celebración misma del seguro el tomador estaba planeando la defraudación de la aseguradora, toda vez que le permite a esta rescindir el contrato y escapar así a la obligación indemnizatoria. Y solamente las interpretaciones sui generis de la Corte Constitucional, que parecen estar siendo revisadas, ponen en peligro la protección de los intereses del sector asegurador ante este tipo de defraudación.

\section{LA CONTRATACIÓN DOLOSA VS. LA CAUSA ILÍCITA}

Como se ya se describió, el contrato de seguro contiene un régimen especial de vicios del consentimiento y por lo tanto, para saber si un contrato de seguro además puede estar afectado por una causa ilícita, es necesario contrastar la regulación de esta, con dicho régimen.

Para el estudio de la causa es necesario remitirse al artículo 1524 del Código Civil. Respecto de este, es importante recordar que en él, don Andrés Bello integró la doctrina sobre las causas de obligaciones nacidas en contratos propuesta por Domat (según la cual las causas de estas eran la contraprestación, en las obligaciones derivadas de contratos bilaterales, la mera liberalidad, en las derivadas de contratos gratuitos, y la entrega, en las derivadas de contratos reales) con la doctrina sobre los móviles que conducían a la celebración de los negocios jurídicos. La licitud o ilicitud de la causa, se refiere a la causa este último sentido.

Así entendida, la causa lícita está consagrada en el artículo 1502 del Código Civil como un requisito necesario diferente al de que el consentimiento no adolezca de vicio. Y la falta de causa lícita tiene una consecuencia distinta al consentimiento viciado, particularmente, la nulidad absoluta del contrato.

A diferencia de lo que pasa parcialmente con los vicios del consentimiento, el deber de declarar sinceramente el estado del riesgo no reemplazan para el contrato de seguro el régimen general de los contratos sobre la causa, toda vez que se trata de requisitos diferentes para la 
validez de los actos o contratos ${ }^{25}$. Sin embargo, aunque la causa lícita es un elemento independiente del consentimiento libre de vicios, no puede predicarse de unos mismos hechos la constitución de una causa ilícita y del dolo como vicio del consentimiento. En este sentido se pronunció la Corte Suprema de Justicia en sentencia de 18 de octubre de 1995, en la cual una aseguradora solicitaba que se declarase absolutamente nulo un contrato de seguro, alegando que su causa era ilícita, toda vez que el móvil del tomador al contratarlo era defraudar al asegurador.

En este caso la Corte indicó que el dolo como vicio del consentimiento nunca degenera en una causa ilícita y que "la reticencia de quien aparece en él como tomador, siendo amañada o intencional, apenas conforma una especie calificada del dolo dispuesta bajo los términos y consecuencias señaladas en el artículo 1058 del código mercantil [...] Y siendo reprimido el dolo, entonces, únicamente con la sanción de la nulidad relativa, no asoma ninguna posibilidad de trastocar ese preciso efecto por el de la nulidad absoluta, ni siquiera acudiendo al régimen común o general”.

En este sentido, las maquinaciones del tomador, sus trampas o artificios encaminados a sorprender al asegurador y a provocar su adhesión, bien sea sobre el contrato en general o sobre ciertas condiciones del mismo, son constitutivas de dolo, y no de causa ilícita, pues el asegurador coloca el seguro viciado por un error provocado por estos artificios fraudulentos y por lo tanto se rige por lo dispuesto en el artículo 1058 y 1059 del Código de Comercio.

Pero diferente es el caso cuando, sin que se vicie el consentimiento del asegurador o de manera paralela al consentimiento viciado de este, haya hechos independientes que sean constitutivos de causa ilícita. Piénsese por ejemplo en el empleador que toma seguros de vida a favor de sus empleados a raíz de un pacto que hizo con ellos de no cotizar al régimen de pensiones; o aquel que toma un seguro de vida a cambio de que un tercero defraude a sus herederos para favorecer al tomador; o el caso del

25 En este sentido se pronuncia el profesor Ossa, afirmando este que "[1]o cierto es que una cosa es la ausencia de consentimiento, de capacidad, de objeto o de causa, como elementos esenciales de todo contrato, de la cual se deriva su inexistencia o su nulidad absoluta y otra el consentimiento viciado por error, fuerza o dolo, que generan su nulidad relativa y dan derecho a su rescisión” (1991, pág. 335). 
que toma un seguro de cumplimiento con el fin de recibir el anticipo de un contrato y luego huir del país.

En todos estos casos, independientemente de que haya habido o no hechos que vicien el consentimiento del asegurador, existen hechos independientes que configuran causas ilícitas, pues los móviles de los tomadores atentan contra la ley o contra las buenas costumbres, lo cual conduce a la nulidad absoluta de los contratos de seguro, no en virtud de lo dispuesto en el artículo 1058 del Código de Comercio, sino de las normas generales del derecho civil y comercial sobre la causa.

La inaplicación del régimen de la causa ilícita al contrato de seguro de la forma descrita daría pie a que este pudiese ser utilizado como vehículo para defraudar a terceros y por lo tanto, de enfrentarse a casos como los descritos, se esperaría que los jueces declararan la nulidad absoluta del contrato, tutelando así los intereses del sector asegurador y de la comunidad en general.

\section{EL SINIESTRO INTENCIONAL Y LA MALA FE EN LA RECLAMACIÓN}

El siniestro intencional, esto es, la causación deliberada del siniestro por parte del tomador, asegurado o beneficiario, es la típica encarnación del fraude duro. Esta provocación deliberada es consecuencia, entonces, de un comportamiento doloso de alguno de los tres sujetos referidos ${ }^{26}$. Sobre el particular el artículo 1055 del Código de Comercio dispone que "[e]l dolo, la culpa grave y los actos meramente potestativos del tomador, asegurado o beneficiario son inasegurables" y que por lo tanto "[c]ualquier estipulación en contrario no producirá efecto alguno". Esta limitación excluye de cobertura cualquier siniestro que ocurra de manera intencional o fraudulenta y así lo deja claro la exposición de motivos del proyecto de Código de Comercio de 1958 cuando indica que en virtud de este artículo "[n]o habrá, pues, base alguna para invocar la posibilidad de una seguro para los siniestros cuya consumación sea provocada intencionalmente" (Ossa Gómez, 1991, pág. 586).

26 Es importante en este escenario distinguir el dolo, entendido como el siniestro deliberadamente provocado, del dolo entendido como vicio del consentimiento. 
En adición a la prohibición del Código de Comercio de asegurar los siniestros causados intencionalmente por el tomador, asegurado o beneficiario, la ley colombiana ha combatido el fraude en el contrato de seguro incluso desde la esfera del derecho penal. Es así como por ejemplo el Código Penal de 1936 establecía en su artículo 418, como tipo penal independiente, que era delito destruir, ocultar o deteriorar objetos asegurados propios para obtener para sí o para un tercero el precio del seguro. Por su parte el Código Penal vigente establece en su artículo 246 que la estafa, entendida como obtener "provecho ilícito para sí o para un tercero, con perjuicio ajeno, induciendo o manteniendo a otro en error por medio de artificios o engaños", es un delito sancionado con entre dos y ocho años de prisión; y en el 2007 la Ley 1142 consagró que la pena sería entre cuatro y ocho años si la estafa estaba relacionada con contratos de seguro.

Ahora, diferente a la provocación intencional o dolosa del siniestro, es la reclamación con mala fe por parte del asegurado o beneficiario. En el primero se está ante una situación en la cual, como se indicó, no puede haber cobertura por parte de un contrato de seguro; en el segundo se está ante un siniestro que, en principio podría estar cubierto, pero en el cual el asegurado altera su descripción del mismo, la documentación que lo soporta o las demás circunstancias que lo rodean con el fin de mejorar la probabilidad de que el evento sea atendido por la compañía aseguradora o que la indemnización sea superior a aquella a la que realmente tendría derecho ${ }^{27}$. Se está entonces frente al fraude suave.

Sobre la mala fe en la reclamación el artículo 1078 del Código de Comercio establece que la misma causará la pérdida del derecho a la indemnización. Esta sanción procura disuadir el fraude suave, toda vez que con la sanción consagrada, el asegurado o beneficiario se está exponiendo no solo a no recibir aquella ventaja adicional que pretende, sino también a perder aquella parte de la indemnización que hubiese recibido de no haber sido por su mala fe en la reclamación.

Ahora, cuando la mala fe en la reclamación concurre con la provocación intencional o dolosa del siniestro, el artículo 1078 del Código de

27 Sin duda que en los casos en los cuales el asegurado o beneficiario provocaron intencional o dolosamente la ocurrencia del siniestro habrá también mala fe en la reclamación, pero la mala fe en la reclamación se presenta también en casos diferentes. 
Comercio también sirve para combatir el fraude duro, pues está otorgando a las compañías de seguros causales adicionales de objeción a la 'simple' prohibición de cubrir el dolo del tomador asegurado o beneficiario, dolo que, en algunos casos, puede resultar más difícil de probar que la mala fe en la reclamación.

\section{EL PRINCIPIO INDEMNIZATORIO, EL SOBRESEGURO Y LA COEXISTENCIA DE SEGUROS}

Los artículos 1088 y 1089 establecen que los seguros de daños se rigen por el principio indemnizatorio y que, como consecuencia, estos jamás podrán ser fuente de enriquecimiento para los asegurados. Entre sus múltiples funciones, el principio indemnizatorio ha sido considerado un freno al fraude pues en defecto de este "el seguro sería un permanente estímulo a la provocación intencional del siniestro" (Ossa Gómez, 1991, pág. 129). En concordancia con el principio indemnizatorio y con el fin de caucionarlo (Ossa Gómez, 1991, pág. 187), el Código de Comercio regula las hipótesis de sobre seguro y coexistencia de seguros entre los artículos 1091 y 1093.

Respecto del sobreseguro, el artículo 1091 dispone que el mismo producirá "la nulidad del contrato, con retención de la prima a título de pena, cuando de parte del asegurado haya habido intención manifiesta de defraudar al asegurador" y que en "los demás casos podrá promoverse su reducción por cualquiera de las partes contratantes, mediante la devolución o rebaja de la prima correspondiente al importe del exceso y al período no transcurrido del seguro." En este sentido el sobreseguro ha sido clasificado por el profesor Ossa (1991, págs. 147-150) en doloso e inocente. Ahora, el sobreseguro doloso, indica Ossa, solo se presenta en la contratación o en el aumento del valor asegurado, pero no por no reducir el valor, pues esa es una facultad, no una obligación y no hacerlo trae una consecuencia diferente.

Esta norma procura prevenir tanto el fraude duro como el suave, pues castiga el sobreseguro con intención manifiesta de defraudar (fraude duro), pero a su vez promueve una adecuación del valor asegurado en todo momento, solo permitiendo la devolución de la prima correspondiente al periodo no transcurrido, lo que disminuye la 'tentación' de 
quedar mal asegurado por si eventualmente ocurre un siniestro, previniendo el fraude suave.

Sobre la coexistencia el artículo 1092 dispone que la mala fe en la contratación de seguros plurales o coexistentes produce su nulidad. Y luego, a renglón seguido, en el artículo 1093 se establece que "[e]1 asegurado deberá informar por escrito al asegurador los seguros de igual naturaleza que contrate sobre el mismo interés, dentro del término de diez días a partir de su celebración" y que "[1]a inobservancia de esta obligación producirá la terminación del contrato, a menos que el valor conjunto de los seguros no exceda el valor real del interés asegurado".

A estas dos normas se suma la consagrada en el artículo 1076 que indica que "el asegurado estará obligado a declarar al asegurador, al dar la noticia del siniestro, los seguros coexistentes [... y que] La inobservancia maliciosa de esta obligación le acarreará la pérdida del derecho a la prestación asegurada".

Estas tres reglas han sido criticadas por, aparentemente, regular tres veces el mismo supuesto de hecho ${ }^{28}$. Sin embargo algunos doctrinantes también han defendido que es posible encontrar ámbito de aplicación a cada una (Ossa Gómez, 1991, pág. 166). Más allá de estas discusiones generales, lo verdaderamente relevante en este análisis es si las sanciones o consecuencias establecidas para la coexistencia de seguros dependen o no de la ausencia de buena fe o intención fraudulenta.

Por su parte en el artículo 1092 es claro que la nulidad procede en el caso de mala fe. En cambio, frente al artículo 1093 el que la no notificación del seguro coexistente contratado requiera de mala fe para producir la terminación, es objeto de debate: por un lado el profesor Ossa (1991, pág. 166) considera que la buena fe no es irrelevante y que la terminación solo se produce si se incumple maliciosamente el deber de aviso; lo anterior porque el 1092 y el 1076 exigen mala fe y no habría razón para que el 1093 fuese más exigente que los otros, en particular que el 1076 que exige informar la coexistencia en un momento en el que

28 En este sentido se puede ver, por ejemplo, los trabajos de los profesores López Blanco (2010, págs. 187-190) y de Ordóñez (2004, págs. 86-90) 
el fraude es más inminente. Sin embargo esta postura no es unánime y otros doctrinantes como López Blanco (2010, pág. 189) abogan por una interpretación literal del artículo 1093 que en su texto no exige en ningún momento que el motivo de la omisión sea la mala fe.

Sobre el artículo 1076 no hay duda de que la pérdida al derecho a la indemnización que consagra por el no aviso de los seguros coexistentes habiendo ocurrido el siniestro está condicionada a la mala fe. Lo que no es pacífico es su alcance: ¿aplica a todos los seguros o solo a los seguros de daños? Ossa (1991, págs. 416-417) opina que solo aplica a los seguros regidos por el principio indemnizatorio pues sostiene que está concebido para prevenir el fraude al principio indemnizatorio, lo anterior a pesar de que se encuentre en el acápite de normas que aplican a todos los seguros terrestres. Sin embargo, la coexistencia puede ser síntoma de fraude incluso en los seguros de personas que no están regidos por el principio indemnizatorio (en especial de fraude duro), por lo tanto, el cumplir el deber de información también puede ser importante frente a ellos y no habiendo distinguido la ley en dicho punto, no le correspondería al intérprete distinguir (López Blanco, 2010, pág. 190).

Esta segunda interpretación sería más acorde con el interés, que debe tener el legislador, de disuadir los comportamientos fraudulentos.

\section{CONCLUSIONES}

El propósito de este trabajo era analizar las reglas que en Colombia desincentivan y castigan la mala fe y el fraude en el contrato de seguro. Como se pudo evidenciar estas reglas regulan comportamientos o situaciones presentes en la etapa precontractual, situaciones atinentes al siniestro o a la reclamación y desarrollan el principio indemnizatorio.

Tanto el deber de declarar sinceramente el estado del riesgo, la prohibición de contratar seguros con causas o motivos ilícitos, la prohibición de cubrir o asegurar los siniestros ocasionados intencional o dolosamente por el tomador, asegurado o beneficiario, el deber de presentar las reclamaciones en buena fe y la regulación del sobreseguro y de la coexistencia de seguros promueven la buena fe y procuran brindar a las compañías 
de seguros con herramientas para enfrentar las diferentes modalidades de frauden en Colombia.

El fraude duro encuentra efectiva protección cuando desde la etapa precontractual se sanciona la contratación maliciosa de seguros, sea porque se maquinan formas de engañar al asegurador para que consienta de manera viciada, sea porque se contrata el seguro con móviles o motivaciones ilícitas. También se protege cuando se prohíbe la cobertura de siniestros causados de manera intencional.

Por su parte, el fraude suave también es adecuadamente atendido cuando se dispone que las reclamaciones en mala fe dan lugar a que se pierda, no solo el beneficio adicional que con el engaño se pretende lograr, sino toda la indemnización. Lo mismo sucede cuando se castiga la no adecuación oportuna de la suma asegurada al disponerse que la devolución de la prima solamente procede a partir de la reducción suma.

El desarrollo e interpretación de la doctrina y de la jurisprudencia de todas las normas revisadas ha sido extenso y enriquecedor y, si bien existen puntos en los que no hay consenso y hay interpretaciones recientes de la Corte Constitucional que se distancian de las tradicionales, el derecho aplicable a las circunstancias estudiadas es en gran medida pacífico. Consecuentemente, el sector asegurador puede encontrar seguridad en un grupo de normas que procuran disuadir la mala fe y el fraude y que, en aquellos casos en los que lamentablemente esto no sucede, les brindan herramientas de defensa que tutelan sus intereses.

\section{BIBLIOGRAFÍA}

Botes, J. H. (2006). From Good Faith to Utmost Good Faith in Marine Insurance. Peter Lang.

de la Espriella, C. (2013). Fraude en seguros: una aproximación al caso colombiano. En R. Junguito, \& M. J. Vargas, La industria aseguradora en Colombia: avances en el Siglo XXI. Bogotá D.C.: Fasecolda.

Díaz Bravo, A. (2009). El fraude y su incidencia en el contrato de seguro. Bogotá D.C.: Pontificia Universidad Javeriana.

Fernández, L. J., Niño, F., \& Cabrera, J. E. (2005). El fraude a los seguros. I(48). 
Jaramillo Jaramillo, C. I. (2011). Derecho de seguros (Vol. II). Bogotá D.C.: Temis.

Jaramillo Jaramillo, C. I. (2016). Principios rectores y reglas de interpretación de los contratos. Bogotá D.C.: Ibáñez; Pontificia Universidad Javeriana.

López Blanco, H. F. (2010). Comentarios al contrato de seguro. Bogotá D.C.: Dupré.

Neme Villareal, M. L. (2006). El principio de buena fe en materia contractual en el sistema jurídico colombiano. Revista de Derecho Privado Externado(11), 79-125.

Neme Villareal, M. L. (2009). Buena fe subjetiva y buena fe objetiva. Equívocos a los que conduce la falta de claridad en la distinción entre tales conceptos. Revista de Derecho Privado Externado, 45-76.

Ordóñez Ordóñez, A. (2003). Inexactitud y Reticencia en la Declaración del Estado del Riesgo a Través de Dos Sentencias de la Corte Suprema de Justicia Colombiana. E-Mercatoria, $I I(1)$.

Ordóñez Ordóñez, A. (2004). Lecciones de Derecho de Seguros N.o 3: Las Obligaciones y Cargas de las Partes en el Contrato de Seguro y la Inoperancia del Contrato de Seguro. Bogotá D.C.: Universidad Externado de Colombia.

Ordóñez Ordóñez, A. (2005). El Tratamiento Civil de la Mala Fe del Asegurado en el Contrato de Seguro. II(4).

Ospina Fernández, G., \& Ospina Acosta, E. (2005). Teoría general del contrato y del negocio jurídico. Bogotá D.C.: Temis.

Ossa Gómez, E. (1991). Teoría general del seguro, el contrato. Bogotá, D.C.: Temis.

Tamayo Jaramillo, J. (2007). Tratado de responsabilidad civil (Segunda ed., Vol. I). Medellín: Legis.

Vásquez Vega, D. (2014). A comparative analysis of utmost good faith in Colombian and English insurance law. $I I(5)$.

Zimmermann, R., \& Whittaker, S. (2000). Good Faith in European Contract Law. Cambridge University Press. 
